\title{
Curative and health enhancement effects of aquatic exercise: evidence based on interventional studies
}

This article was published in the following Dove Press journal:

Open Access Journal of Sports Medicine

28 March 2012

Number of times this article has been viewed

\author{
Takuya Honda' \\ Hiroharu Kamioka ${ }^{2}$ \\ 'Research Fellow of the Japanese \\ Society for the Promotion of Science, \\ ${ }^{2}$ Laboratory of Physical and Health \\ Education, Faculty of Regional \\ Environment Science, Tokyo University \\ of Agriculture, Tokyo, Japan
}

Background: The purpose of this study was to report on the health benefits and curative effects of aquatic exercise.

Methods: We adopted the results of high-grade study designs (ie, randomized controlled trials and nonrandomized controlled trials), for which there were many studies on aquatic exercise. Aquatic exercise, in this study, means walking in all directions, stretching, and various exercises and conditioning performed with the feet grounded on the floor of a swimming pool. We excluded swimming. We decided to treat aquatic exercise, underwater exercise, hydrotherapy, and pool exercise as all having the same meaning.

Results: Aquatic exercise had significant effects on pain relief and related outcome measurements for locomotor diseases.

Conclusion: Patients may become more active, and improve their quality of life, as a result of aquatic exercise.

Keywords: aquatic exercise, health enhancement, evidence

\section{Introduction}

In recent years, Japan has become a fast-aging population, with the greatest longevity in the world. According to statistics released by the Japanese Health, Labor, and Welfare Ministry, the proportion of Japanese aged 65 years and older reached $20.8 \%$ in 2006, and is estimated to reach $39.6 \%$ by 2050 . Total national medical costs were about US\$262 billion, while the national income of Japan was about US\$3.05 trillion. ${ }^{1}$ The national medical cost in 2002 was $8.58 \%$ of national income and has been increasing each year. When the national medical cost is divided among those aged 65 years or older, and those younger than 65 years, the costs of the former amount to \$US128 billion ( $\$ 5428$ per person per year), while the cost for the latter is US\$133 billion ( $\$ 1285$ per person per year). This indicates that overall medical costs for the elderly are extremely high in Japan. According to records for April, 2004, the number of beneficiaries of public care insurance was about 3,140,000, at a cost of about \$US46 billion. Since the current insurance care system may go bankrupt without revision, the establishment of a "prevention-oriented (care prevention) system" was suggested in the revised care insurance system that was implemented in April, 2006.

The prevalence of obesity and metabolic syndrome (MS) is increasing in many industrialized countries. This situation also exists in Japan. The prevalence of MS, diagnosed according to Japanese criteria, was $18.4 \%$ and $5.8 \%$ for men and women, respectively. ${ }^{2}$ Among the indicators of MS, high blood pressure was most frequently observed, followed by dyslipidemia. High fasting plasma glucose occurred least frequently in both sexes. 
The health benefits of physical activity are well documented for middle-aged and elderly people. Increasing physical activity has been shown to be effective for the prevention of coronary heart disease, stroke, diabetes, obesity, and hypertension, and for the improvement of quality of life (QOL) and mental health. ${ }^{3-8}$

There are many studies on exercise, but there are few reports that summarize the results of evidence grading of water exercise. Therefore, this study reports on the health benefits and curative effects of aquatic exercise.

Aquatic exercise, in this study, means walking in all directions, stretching, and various exercises and conditioning, with the feet grounded on the floor of a swimming pool. Regardless of sex and age, swimming is not an exercise that many people can perform. We decided to treat aquatic exercise, underwater exercise, hydrotherapy, and pool exercise as having the same meaning. In all geographic areas, except the tropics, a warm-water swimming pool was used (approximately $30^{\circ} \mathrm{C}$ ).

\section{Concept of evidence grading for evaluating curative and health-enhancement effects 9}

The concept of evidence grading is used in evidence-based medicine and in evidence-based health policy. The concept is supported worldwide, in both epidemiological and clinical studies (Table 1). Grades considered most likely to provide convincing evidence are Grade I: "evidence (systematic review [SR]) obtained from meta-analyses of randomized controlled trials (RCTs);" and Grade II, defined as "evidence obtained from at least one RCT." The lowest grade, indicating the least convincing evidence, is Grade VI: "evidence (without data) obtained from expert committee reports or opinions and/ or clinical experience of respected authorities." If a study receives two different grades, the upper rank is adopted. RCTs, in particular, have recently been gaining attention in

Table I Evidence grading (US Agency for Health Care Policy and Research)

\footnotetext{
I. Evidence systematic review obtained from meta-analysis of RCTs

II. Evidence obtained from at least one RCT

III. Evidence obtained from at least one well controlled study without randomization

IV. Evidence obtained from observational study

V. Evidence obtained from descriptive study

VI. Evidence (without data) obtained from expert committee reports or opinions and/or clinical experience of respected authorities

Abbreviation: $\mathrm{RCT}$, randomized controlled trial.
}

epidemiological and clinical studies, because they are the most effective study design for controlling for differences among humans, and can successfully show the effects of certain interventions (eg, tai chi exercise). We adopted the results of high-grade study designs, of which there were many for studies on aquatic exercise.

\section{SR of SRs of RCTs for aquatic exercise}

A systematic review of SRs of RCTs reported that aquatic exercise had small but statistically significant effects on pain relief and related outcome measures for locomotor diseases (eg, arthritis, rheumatoid diseases, and lower back pain). However, the long-term effectiveness was unclear. ${ }^{10}$ Our study was based on a review of articles in databases from 1990 to August 17, 2008. We described the structured abstract of three SRs (Table 2). The SRs of aquatic exercise showed a curative effect in all studies. Aquatic exercise had a small but statistically significant effect on pain, function, QOL, and mental health, and included more voluntary movement during water immersion. However, it should be noted that this was only the immediate effect of intervention, and not the long-term result. The intervention periods ranged from 3 weeks to 12 months in aquatic exercise studies. This might reflect the difficulty of maintaining long-term participation in an RCT. Whatever the case, the long-term effects are not clear.

Overall, aquatic exercise had a small (but statistically significant) effect on pain relief and related outcome measurements for locomotor diseases.

\section{SR of nonrandomized controlled trials (nRCTs)}

A current SR of nRCTs reported that 21 trials met inclusion criteria. ${ }^{11}$ The study was based on a review of articles in databases from 2000 to July 20, 2009. Target diseases were knee and/or hip osteoarthritis, ${ }^{12-14}$ poliomyelitis, ${ }^{15}$ chronic kidney disease, ${ }^{16}$ discomforts of pregnancy, ${ }^{17}$ cardiovascular diseases, ${ }^{18}$ and rotator cuff tears. ${ }^{19}$ Many studies on nonspecific disease (healthy participants) were included. ${ }^{20-32}$ All studies reported significant effectiveness for one or more outcomes. In particular, many studies reported that aquatic exercise had a significant effect on pain relief and other outcome measurements for locomotor diseases. ${ }^{12-15,19}$ Intervention periods ranged from 2 weeks to 12 months.

Table 3 shows the future research agenda for aquatic exercise. ${ }^{11}$ In advanced nations, it appears that there is interest 


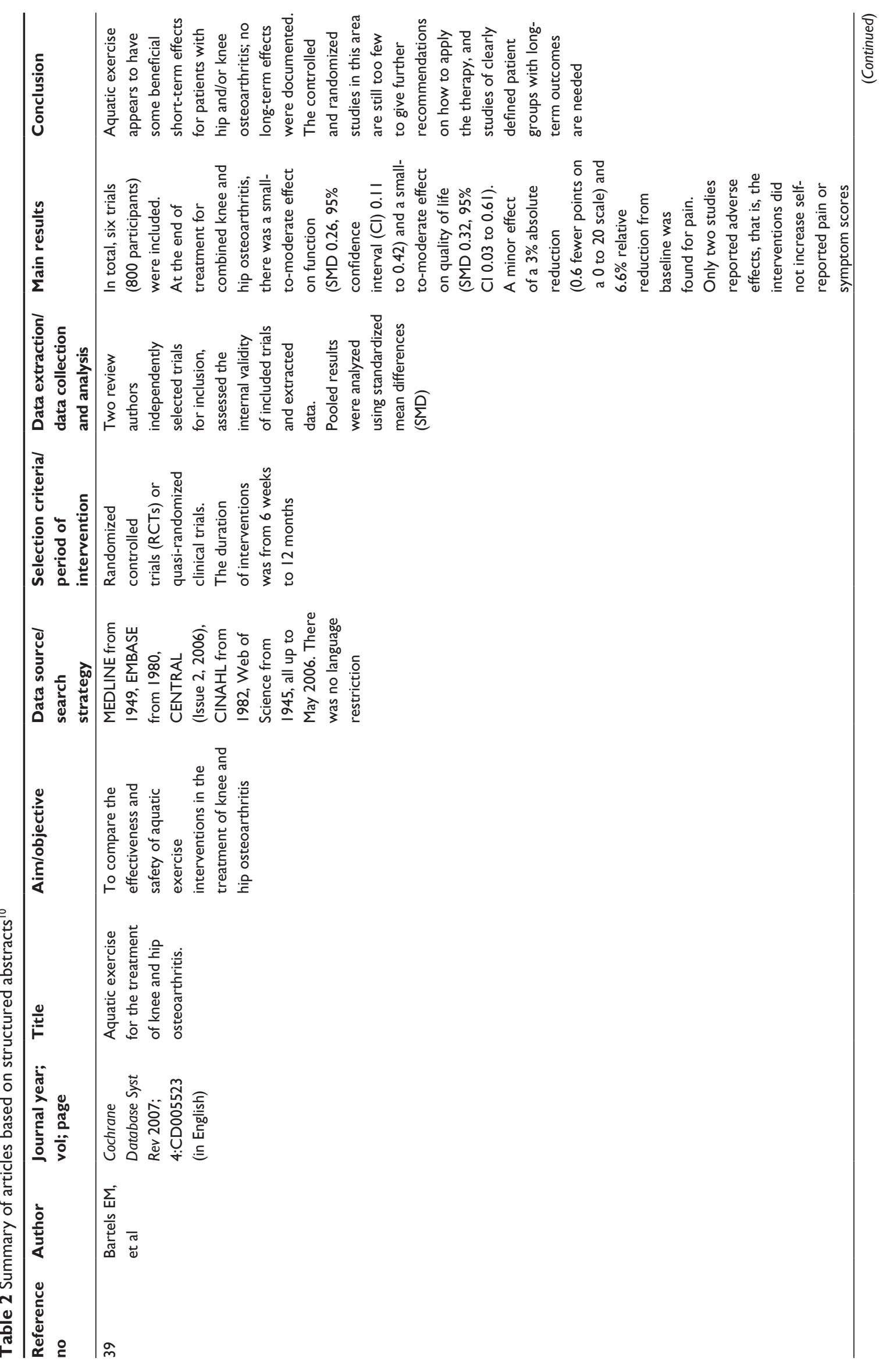




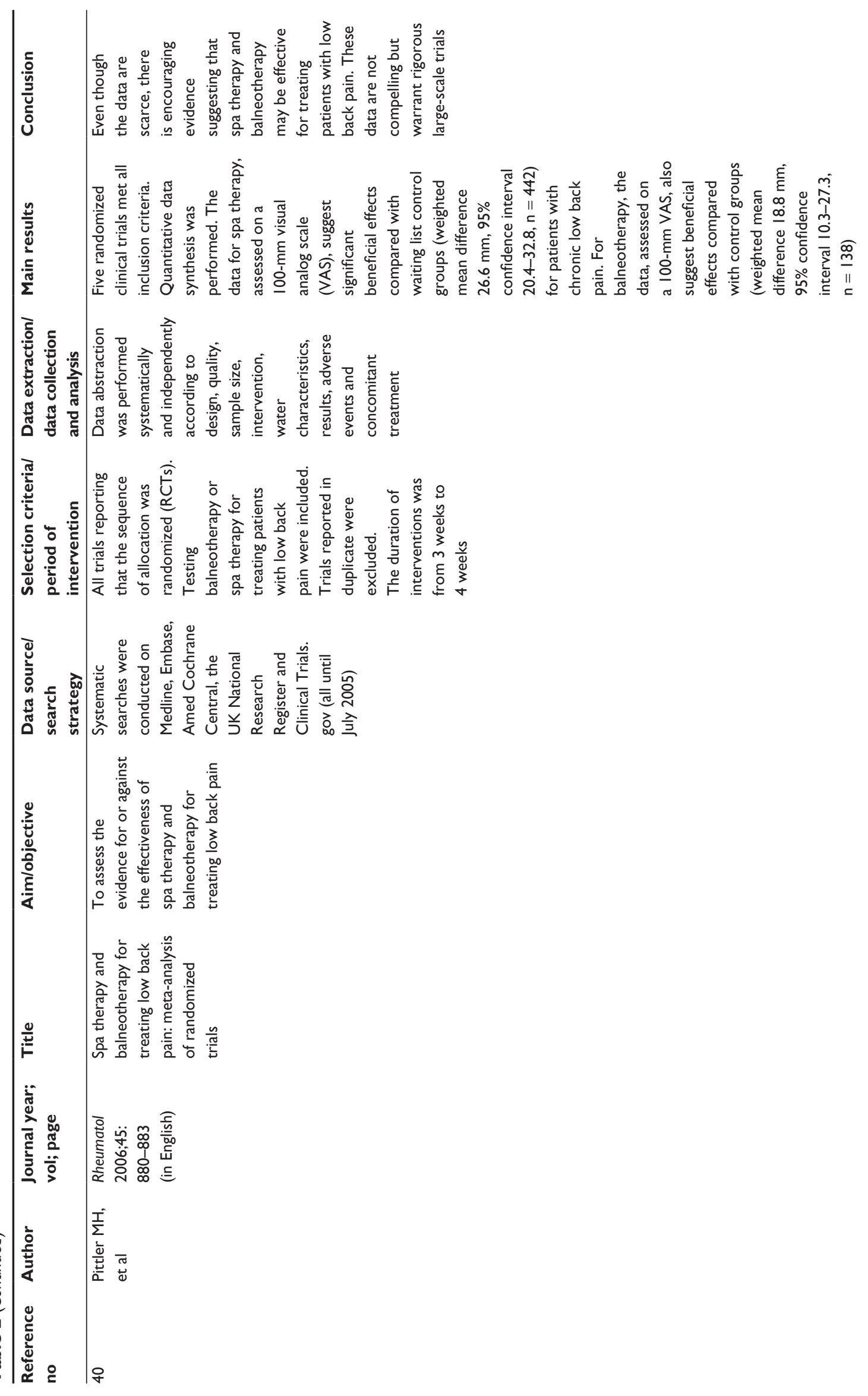




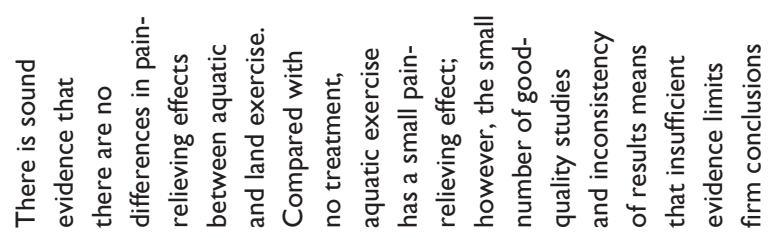

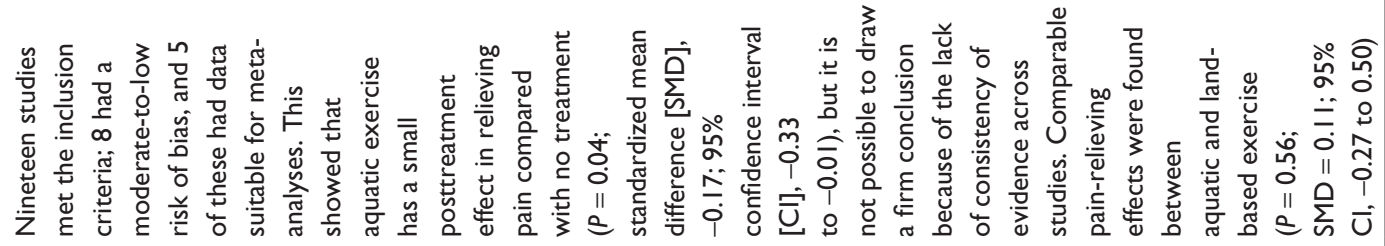

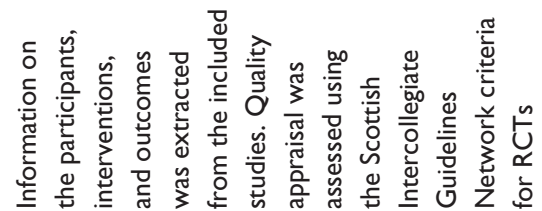

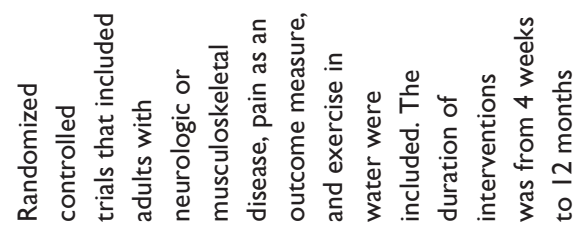
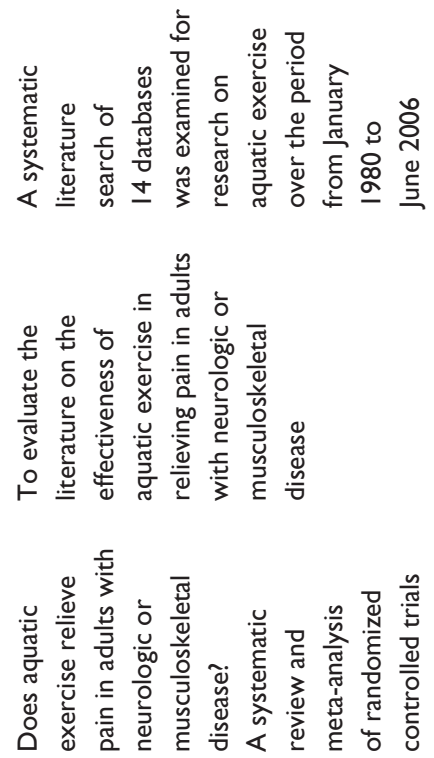

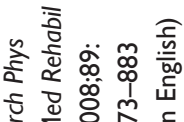

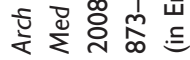

$\bar{\square}$
$\stackrel{\overline{0}}{\overline{\bar{I}}}$

$\bar{\gamma}$ 
Table 3 Future research agenda on aquatic exercise intervention"1

\begin{tabular}{|c|c|}
\hline Item & Concrete agenda \\
\hline $\begin{array}{l}\text { Target disease* or } \\
\text { prevention }\end{array}$ & $\begin{array}{l}\text { I. The prevention and curative effect of } \\
\text { metabolic syndrome } \\
\text { 2. The prevention and the curative effect of } \\
\text { mental diseases such as depression }\end{array}$ \\
\hline $\begin{array}{l}\text { Strengthening } \\
\text { of quality }\end{array}$ & $\begin{array}{l}\text { I. Set of research protocol, practice, } \\
\text { description based on each respective checklist } \\
\text { 2. Description of adverse event and withdrawal }\end{array}$ \\
\hline $\begin{array}{l}\text { Feasibility and intrinsic } \\
\text { characteristic }\end{array}$ & $\begin{array}{l}\text { I. Comparison with land exercise and/or the } \\
\text { other dynamic intervention } \\
\text { 2. Description of intervention cost }\end{array}$ \\
\hline
\end{tabular}

Note: $*$ The pain-relieving effect of chronic locomotorium diseases has already become clear from many RCTs.

Abbreviation: $\mathrm{RCT}$, randomized controlled trial.

in studies about mental health, as well as MS. Researchers should use the respective checklists for research design and intervention methods, which should lead to improvement in the quality of the study and contribute to the accumulation of evidence. Suitable comparisons are necessary to explain why aquatic exercise is better than other types of dynamic exercise. Aquatic exercise needs a valuable resource (hot water pool), which cannot be overlooked with respect to study feasibility.

\section{Mechanism of pain relief for locomotor diseases}

The warmth and buoyancy of water may block nociception by acting on thermal receptors and mechanoreceptors, thus influencing spinal segmental mechanisms. ${ }^{33,34}$ In addition, warm water may enhance blood flow, which is thought to help in dissipating algogenic chemicals and facilitating muscle relaxation. The hydrostatic effect of water may relieve pain by reducing peripheral edema ${ }^{35}$ and by dampening sympathetic nervous system activity. ${ }^{36}$ We should regard a mechanism to relieve the pain of locomotor diseases as a complex of factors, not as one factor.

\section{Effects and expectations that accompany pain relief}

People with obesity and MS become inactive and tend to be reluctant to perform physical activity. Therefore, due to weight gain and/or inactivity, they develop locomotor diseases, which include knee and back pain. It is also known that weight increases exacerbate obesity and MS.

Figure 1 shows the effects and expectations from aquatic exercise. Pain, in particular, limits the activity of people. There are various exercises that do not cause worsening of symptoms (pain). For aquatic exercise, the complex effect is great. It is certain that aquatic exercise has the effect of pain relief in locomotor diseases, and, as a result, patients may become more active and improve their QOL. Recent reports have demonstrated that comprehensive health education, which includes a combination of lifestyle education and aquatic exercise, has positive effects for middle aged and elderly people. ${ }^{37,38}$

Physical and mental health enhancement/improvement of QOL

$\uparrow$

Weight loss/improved metabolism/pain-relief

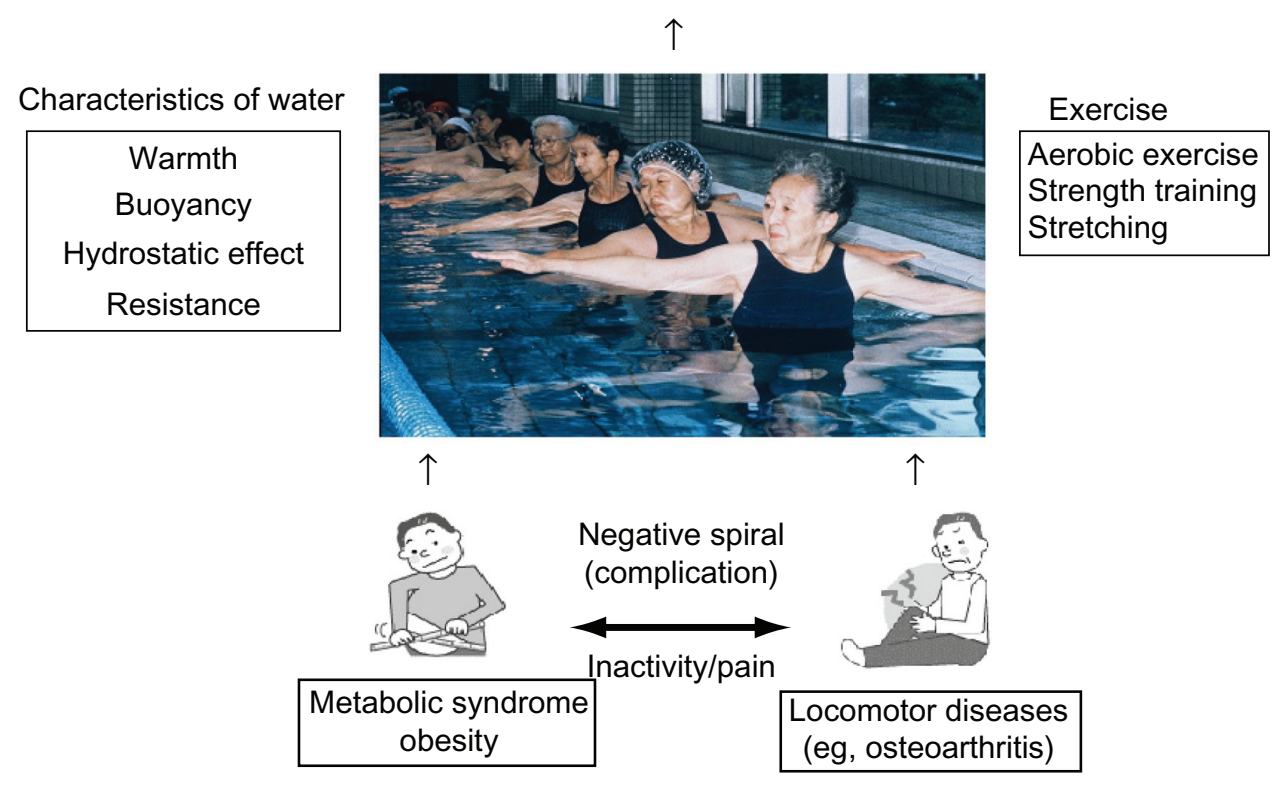

Figure I Effects and expectations from aquatic exercise. 


\section{Study limitations}

There were some limitations to this study, as described above. Some selection criteria were common to the source studies. However, bias remained, due to differences in eligibility for participation in each study. Publication bias was also a limitation.

\section{Conclusion}

Aquatic exercise has significant effects on pain relief and related outcome measurements for locomotor diseases. Patients may become more active and improve their QOL as a result of aquatic exercise.

\section{Acknowledgments}

This study was supported by a Grant In Aid for Scientific Research (Representative Researcher, Prof H Kamioka) from the Ministry of Education, Culture, Sports, Science and Technology, Japan, 2011. We would like to express our appreciation to Ms R Higashino and Ms M Makishi for their assistance in this study.

\section{Disclosure}

The authors report no conflicts of interest in this work.

\section{References}

1. Health and Welfare Statistics Association of Japan. Annual Statistical Report of National Health Conditions. 2006. Japanese.

2. Kobayashi J, Nishimura K, Matoba M, Maekawa M, Mabuchi H. Generation and gender differences in the components contributing to the diagnosis of the metabolic syndrome according to the Japanese criteria. Circ J. 2007;71:1734-1737.

3. Haskell WI, Lee IM, Pate RR. Physical activity and public health: updated recommendation for adults from the American College of Sports Medicine and the American Heart Association. Med Sci Sports Exerc. 2007;39:1423-1434.

4. Peri K, Kerse N, Robinson E. Does functionally based activity make a difference to health status and mobility? A randomized controlled trial in residential care facilities (The Promoting Independent Living Study; PILS). Age Ageing. 2008;37:57-63.

5. Jensen MK, Chiuve SE, Rimm EB. Obesity, behavioral lifestyle factors, and risk of acute coronary events. Circ J. 2008;117: 3062-3069.

6. Ford J, Spallek M, Dobson A. Self-rated health and a healthy lifestyle are the most important predictors of survival in elderly women. Age Ageing. 2008;37:194-200.

7. Dutton GR, Napolitano MA, Whiteley JA, Marcus BH. Is physical activity a gateway behavior for diet? Findings from a physical activity trial. Prev Med. 2008;46:216-221.

8. Mein GK, Shipley MJ, Hillsdon M, Ellison GT, Marmot MG. Work, retirement and physical activity: cross-sectional analyses from the Whitehall II study. Eur J Public Health. 2005;15:317-322.

9. Kamioka H, Shiozawa N, Shimojima H, Hida A, Tada Y, Kawano Y. Significance of checklists for improving the quality of studies of health enhancement interventions: evidence grading and various study designs of epidemiological and clinical studies. Int J Sports Sci Physic Educ. 2011;2(1):1-6.
10. Kamioka H, Tsutani K, Okuizumi H, et al. Effectiveness of aquatic exercise and balneotherapy: a summary of systematic reviews based on randomized controlled trials of water immersion therapies. J Epidemiol. 2010;20(1):2-12.

11. Kamioka H, Tsutani K, Mutoh Y, et al. A systematic review of nonrandomized controlled trials on curative effects of aquatic exercise. Int J General Med. 2011b;4:239-260.

12. Murai E, Takeda Y, Imaya T, Uchiyama E, Nakazono H, Nakajima H. Exercise therapy for osteoarthritis of the knee - preliminarily study of water exercise. J Jpn Soc Clin Sports Med. 2002;10:54-60. Japanese, English.

13. Lin SY-C, Davey RC, Cochrane T. Community rehabilitation for older adults with osteoarthritis of the lower limb: a controlled clinical trial. Clin Rehabil. 2004;18:92-101.

14. Lee HY. Comparison of effects among Tai-chi exercise, aquatic exercise, and a self-help program for patients with knee osteoarthritis. J Korean Acad Nurs. 2006;36:571-580. Korean, English.

15. Willén C, Sunnerhagen KS, Grimby G. Dynamic water exercise in individuals with late poliomyelitis. Arch Phys Med Rehabil. 2001;82: 66-72.

16. Pechter Ü, Ots M, Mesikepp S, et al. Beneficial effects of water-based exercise in patients with chronic kidney disease. Int $J$ Rehabil Res. 2003;26:153-156.

17. Smith SA, Michel Y. A pilot study on the effects of aquatic exercises on discomforts of pregnancy. J Obstet Gynecol Neonatal Nurs. 2006;35:315-323

18. Nishikawa A, Ueda Y, Wakayama K, Hayashi Y. Effect of aquatic walking on the cardiovascular patients in our hospital and health-related QOL - in comparison with indoor exercise therapy. JJCR. 2008;13:135138. Japanese.

19. Brady B, Redfern J, MacDougal G, Williams J. The addition of aquatic therapy to rehabilitation following surgical rotator cuff repair: a feasibility study. Physiother Res Int. 2008;13:153-161.

20. Ebisu T, Kobayashi M, Katsuki T, Yanagimoto Y. Effectiveness of serum lipids on spa-walking. Health Care. 2001;43:981-984. Japanese.

21. Aoba T, Matsumoto T, Sugano A, Nomura T. The effects of enforcement water exercise class on hypotensive to blood pressure at elderly subjects. Ann Reports Health Phys Educ Sports Sci. 2001;20:99-104. Japanese, English.

22. Yamada T, Watanabe E, Okada A, Takeshima N. Effects of water-based well-rounded exercise on vital age and physical fitness in older adults. Jpn Soc Phys Anthropol. 2002;7:87-93. Japanese, English.

23. Igarashi Y, Kondo T, Yamaoka K, et al. Health effect of aquatic exercise therapy using a hot spring. Sick Body Phys. 2002;36:11-14 Japanese.

24. Douris P, Southard V, Varga C, Schauss W, Gennaro C, Reiss A. The effect of land and aquatic exercise on balance scores in older adults. J Geriatr Phys Ther. 2003;26:3-6.

25. Liquori A, Widener G, Clark L. Effects of a 6-week prenatal water exercise program on physiological parameters and well-being in women with pregnancies in the 2 nd-3rd trimesters: a pilot study. $J$ Section Women's Health. 2003;27:11-19.

26. Akamine T, Yamanaka T, Taguchi N, et al. Effects of underwater exercise with hot spring bathing on middle aged people. Kyushu Yamaguchi Sports Sci J. 2005;17:7-12. Japanese, English.

27. Takumi Y, Moriya K, Oda S, Adikari MO, Fukuoka E. Participation in an aquatic exercise class twice a week for 12 weeks improved physical fitness for good walking, walking self-efficacy on winter roads, mental health and QOL in elderly women. Jpn J Biometeor. 2005a;42:17-27. Japanese, English.

28. Takumi Y, Moriya K. Participation in an aquatic walking class for 12 weeks improved physical fitness for good walking, emotion and walking self-efficacy on winter roads in middle-aged and elderly women. Jpn J Biometeor. 2005b;42:5-15. Japanese, English.

29. Lord SR, Matters B, George RS, et al. The effects of water exercise on physical functioning in older people. Australasian J Ageing. 2006;25:36-41. 
30. Chishaki A, Makaya M, Nagahiro C, et al. Comparison of usefulness between water exercise and gymnastic exercise, Jikyojyutsu, in maintaining physical ability for the elderly. Memoirs Dep Health Sci Sch Med Kyushu Univ. 2006;7:23-32. Japanese, English.

31. Kawasaki T, Muratani H, Ozoe N, Higaki H, Kawasaki J. The effect of aquatic exercise on preventing falls and life-style related disease among middle-aged and elderly people. Jpn J Clin Exper Med. 2007;84:402-411. Japanese.

32. Rotstein A, Harush M, Vaisman N. The effect of a water exercise program on bone density of postmenopausal women. J Sports Med Phys Fitness. 2008;48:352-359.

33. Bender T, Karagülle Z, Bálint GP, Gutenbrunner C, Bálint PV, Sukenik S. Hydrotherapy, balneotherapy, and spa treatment in pain management. Rheumatol Int. 2005;25:220-224.

34. Yamazaki F, Endo Y, Torii R, Sagawa S, Shiraki K. Continuous monitoring of change in hemodilution during water immersion in humans: effect of water temperature. Aviat Space Environ Med. 2000;71:632-639.

35. Gabrielsen A, Videbaek R, Johansen LB, et al. Forearm vascular and neuroendocrine responses to graded water immersion in humans. Acta Physio Scand. 2000;169:87-94.
36. Fam AG. Spa treatment in arthritis: a rheumatologist's view. J Rheumatol. 1991;18:1775-1777.

37. Kamioka H, Ohshiro H, Mutoh Y, et al. Effect of long-term comprehensive health education on the elderly in a Japanese village: Unnan cohort study. Int J Sports Health Sci. 2008;6:60-65.

38. Kamioka H, Nakamura Y, Okada S, et al. Effectiveness of comprehensive health education combining lifestyle education and hot spa bathing for male white-collar employees: a randomized controlled trial with 1-year follow-up. J Epidemiol. 2009;19:219-230.

39. Bartels EM, Lund H, Hagen KB, Dagfinrud H, Christensen R, Danneskiold-Samsøe B. Aquatic exercise for the treatment of knee and hip osteoarthritis. Cochrane Database Syst Rev. 2007;(4):CD005523.

40. Pittler MH, Karagülle MZ, Karagülle M, Ernst E. Spa therapy and balneotherapy for treating low back pain: meta-analysis of randomized trials. Rheumatology. 2006;45:880-884.

41. Hall J, Swinkels A, Briddon J, McCabe CS. Does aquatic exercise relieve pain in adults with neurologic or musculoskeletal disease? A systematic review and meta-analysis of randomized controlled trials. Arch Phys Med Rehabil. 2008;89:873-883.
Open Access Journal of Sports Medicine

\section{Publish your work in this journal}

Open Access Journal of Sports Medicine is an international, peer-reviewed, open access journal publishing original research, reports, reviews and commentaries on all areas of sports medicine. The manuscript management system is completely online and includes a very quick and fair peer-review system.

\section{Dovepress}

Visit http://www.dovepress.com/testimonials.php to read real quotes from published authors. 